\title{
Functional profiling of immediate early gene Egr1 in an anorexic mouse model
}

\author{
JUN HUANG, WEIXI JIANG and DUN YUAN \\ Department of Neurosurgery, Xiangya Hospital, Central South University, Changsha, Hunan, 410008, P.R. China
}

Received May 22,2013; Accepted August 19, 2013

DOI: $10.3892 / \mathrm{mmr} .2013 .1656$

\begin{abstract}
A small population of neurons in the hypothalamus is known to promote food intake by releasing inhibitory agouti-related peptide (ARP) and neuropeptide Y to broad postsynaptic areas. Acute ablation of ARP neurons in adult mice leads to rapid loss of appetite and the development of an anorexic phenotype. Recent studies have suggested that ablation of ARP neurons removes critical inhibition of postsynaptic neurons, resulting in hyperexcitation of selected downstream neurons. Left uncontrolled, this neuronal hyperactivation is hypothesized to induce starvation. However, the cellular mechanism underlying the control of excitability of postsynaptic neurons in response to the ablation of ARP neurons is poorly understood. The present study aimed to determine the functional correlation between ARP neurons and an immediate early gene, early growth response factor-1 (Egrl), in postsynaptic neurons in the context of energy homeostasis. Egrl expression levels were analyzed in different postsynaptic areas upon acute ablation of ARP neurons. As ARP neurons increase appetite by inhibiting the pro-opiomelanocortin pathway, it was also investigated whether blockade of melanocortin signaling affects Egrl expression in ARP neuron-ablated mice. The results suggested that ablation of ARP neurons induced robust expression of Egrl in numerous common postsynaptic targets of ARP and pro-opiomelanocortin neurons. When ARP neurons were acutely ablated, it was demonstrated that Egrl induction was attenuated by chronic blockade of the melanocortin signaling pathway in the arcuate nucleus, but not in other downstream regions. Further analysis of the Egrl signaling cascade may aid in differentiating the functional involvement of postsynaptic targets of ARP neurons in the control of energy metabolism.
\end{abstract}

Correspondence to: Dr Dun Yuan, Department of Neurosurgery, Xiangya Hospital, Central South University, 87 Xiangya Road, Changsha, Hunan 410008, P.R. China

E-mail: yuandunlp@gmail.com

Key words: neuron, energy metabolism, Egrl, agouti-related peptide

\section{Introduction}

Agouti-related protein (ARP) is an orexigenic peptide that modulates appetite and energy balance (1). ARP-expressing neurons also produce neuropeptide Y (NPY) and the inhibitory neurotransmitter GABA $(2,3)$. ARP stimulates robust feeding behavior when injected into the 3rd ventricle or directly into the paraventricular nucleus (PVN) or dorsomedial hypothalamic nucleus (DMH) $(1,4)$. Its mRNA level increases in the arcuate nucleus (ARC) under starvation conditions, as well as in obese animals deficient in leptin signaling (5-8). Several groups have devised strategies whereby ARP neurons are ablated to investigate their involvement in body weight regulation (9-12). One such strategy has been used in adult mice and has demonstrated that ARP neuron ablation leads to the inhibition of feeding behavior (10). In this ablation technique, diphtheria toxin receptors (DTR) were targeted under the control of the Agrp promoter to ensure exclusive expression of DTR in ARP neurons $(9,10)$. Diphtheria toxin (DT) was then administered to adult mice, leading to the ablation of the neurons over the next few days. This treatment led to a significant loss of body weight and the mice were shown to have developed anorexia $(9,10)$. Studies have suggested that ablation of ARP neurons removes NPY and GABA-mediated inhibition of postsynaptic neurons, leading to hyperexcitation of selected downstream brain regions and the induction of starvation behavior (13). However, the cellular mechanism underlying the excitability of postsynaptic neurons in response to ablation of ARP neurons is poorly understood.

The immediate early gene, early growth response factor-1 $(E g r l)$, is a transcription factor that regulates transcriptional responses to cell stimulation in a variety of neurons and other cells. It is rapidly induced by stimuli, such as growth factors or cell depolarization $(14,15)$. Constitutive expression of Egrl has been identified in certain types of neurons (16). In vagal afferent neurons, it has been demonstrated that cholecystokinin (CCK) stimulates the redistribution of Egrl to the nucleus, and leptin stimulates Egrl expression (17). Egrl induces the expression of the gene encoding the satiety neuropeptide, cocaine- and amphetamine-regulated transcript (CART), in the nodose ganglion, which leads to the inhibition of food intake (17).

The present study aimed to determine the functional association between appetite-controlling ARP neurons and Egrl in postsynaptic neurons. Egrl expression levels were investigated in different brain regions following acute 
ablation of ARP neurons. As ARP neurons promote appetite in part through inhibiting the pro-opiomelanocortin (POMC) pathway $(2,3,18)$, it was also investigated whether blockade of melanocortin signaling affects Egrl expression in ARP neuron-ablated mice. It was demonstrated that the death of ARP neurons was associated with robust activation of Egrl expression in selected brain regions. In addition, it was suggested that Egrl may induce a novel signaling cascade in postsynaptic neurons that mediates the feeding response and energy balance.

\section{Materials and methods}

Animal maintenance. Mice were housed in a temperature- and humidity-controlled environment with a 12-h light/dark cycle. All experimental protocols and animal handling procedures were performed according to the protocol approved by the Institutional Animal Care and Use Committee of the Central South University (Changsha, China). Agrp ${ }^{\text {DTR }}$ mice and $\mathrm{A}^{\mathrm{y}}$ mice were obtained from the Jackson Laboratory (Bar Harbor, ME, USA). The Agrp ${ }^{\text {DTR }}$ mice were generated by targeting a human DTR cDNA to the Agrp locus of mice to allow the selective killing of ARP neurons in adult mice by administration of DT. Administration of DT resulted in reliable loss of food consumption and body weight $(9,10)$. The $\mathrm{A}^{\mathrm{y}}$ mice express agouti protein ectopically in virtually all tissues, including the brain (19). Agouti protein antagonizes the action of $\alpha$-melanocyte stimulating hormone ( $\alpha$-MSH) binding to melanocortin 4 receptors (MC4Rs) and thus prevents melanocortin signaling via Gas-coupled receptors on postsynaptic cells (18). $\operatorname{Agrp}^{\mathrm{DTR}}$ mice and $\mathrm{A}^{\mathrm{y}}$ mice were mated together to generate $\mathrm{A}^{\mathrm{y}} ; \operatorname{Agrp}^{\mathrm{DTR} /+}$ mice. The $\mathrm{A}^{\mathrm{y}} ; \operatorname{Agrp}^{\mathrm{DTR} /+}$ mice were generated to determine the consequence of suppressed melanocortin signaling on Egrl gene induction. The yellow mice derived from this cross comprise were the $\mathrm{A}^{\mathrm{y}}$; $\operatorname{Agrp}^{\mathrm{DTR} /+}$ group, whereas the black littermates served as Agrp ${ }^{\text {DTR } /+}$ controls. Mice were group-housed with a standard chow diet and water ad libitum until the beginning of the experiments. To ablate ARP neurons, systemic injection of DT (two injections of $50 \mathrm{mg} / \mathrm{kg}$; Sigma Aldrich, St. Louis, MO, USA) was performed in 9-week-old mice $(9,10)$.

In situ hybridization. Brains were sectioned (coronal, $25 \mu \mathrm{m}$ thickness) and used for in situ hybridization with Egrl probes according to the manufacturer's instructions (Roche, Mannheim, Germany). Materials and detailed procedures concerning the data generation process (riboprobe production, in situ hybridization, image capture and processing) have been described previously (20). Briefly, an antisense Egrl oligonucleotide probe was used for in situ hybridization. Tissue sections were postfixed in $4 \%$ formaldehyde/phosphate-buffered saline (PBS), rinsed in PBS and acetylated in $0.25 \%$ acetic anhydride/ $0.1 \mathrm{M}$ triethanolamine. Hybridization in a solution containing a saturating concentration $(28 \mathrm{kcpm} / \mu \mathrm{l})$ of radiolabeled probe was conducted at $65^{\circ} \mathrm{C}$ for $18 \mathrm{~h}$. Coverslips were removed in $4 \mathrm{X}$ standard sodium citrate and non-specifically bound probe was removed by treatment with RNase (Sigma-Aldrich) for $30 \mathrm{~min}$. Sections were run through stringency washes of $1 \mathrm{X}$ saline sodium citrate (SSC) buffer and $0.5 \mathrm{X} \mathrm{SSC}$ at $37^{\circ} \mathrm{C}$ and $0.1 \mathrm{X} \mathrm{SSC}$ at $42^{\circ} \mathrm{C}$.
Sections were then dehydrated, air-dried and exposed to Kodak BioMax X-ray film (Kodak Inc., Rochester, NY, USA) for 3 days along with microscale 14C standards (GE Healthcare, Little Chalfont, UK).

Statistical analysis. Quantification of Egrl-positive cells was conducted using ImageJ software (National Institutes of Health, Bethesda, MA, USA). Anatomical correlations of brain sections and delineation of individual nuclei were determined by comparing landmarks of Nissl staining images with those provided in the Paxinos stereotaxic atlas (21). From the anatomically matched sections, a region of interest of the same size was further defined. In addition, an optimized threshold that discerns round Egrl-positive nuclei from partially stained ones and background noise was preset for all measurements. The total number of pixels of Egrl-positive cells inside the defined region was recorded. Unless otherwise stated, data were analyzed using one-way analysis of variance followed by a post-hoc Student-Newman-Keuls test. Data are presented as the mean \pm SEM. $\mathrm{P}<0.05$ was considered to indicate a statistically significant difference.

\section{Results}

Ablation of ARP neurons by administration of DT induces Egrl in the ARC. A human DTR cDNA was targeted to the Agrp locus of mice, which allowed the selective killing of ARP neurons in adult mice by administration of DT. Administration of DT has been shown to result in reliable loss of food consumption and body weight $(9,10)$. The cell bodies of all ARP neurons located in the ARC were shown to be completely ablated by DT treatment $(9,10)$. In situ hybridization showed that Egrl expression was robustly induced in the ARC of Agrp ${ }^{\text {DTR }}$ mice following DT treatment (Fig. 1E and F, and Fig. 2A). In contrast, DT treatment in wild type (WT) and pair-fed mice exhibited no effect on Egrl expression (Fig. 1A-D and Fig. 2A).

Induction of Egrl in the ARC is attenuated in the absence of melanocortin signaling. The $\mathrm{A}^{\mathrm{y}}$ mice express agouti protein ectopically in virtually all tissues, including the brain (19). Agouti protein antagonizes the action of $\alpha$-MSH binding to MC4R, and thus prevents melanocortin signaling via the Gas-coupled receptors on postsynaptic cells (18). $\operatorname{Agrp}^{\mathrm{DTR}}$ mice and $\mathrm{A}^{\mathrm{y}}$ mice were mated together to generate $\mathrm{A}^{\mathrm{y}} ; \operatorname{Agrp}^{\mathrm{DTR} /{ }^{+}}$mice. $\mathrm{A}^{\mathrm{y}} ; \operatorname{Agrp}^{\mathrm{DTR} /{ }^{+}}$mice were generated to determine the consequence of suppressed melanocortin signaling on Egrl gene induction. In situ hybridization showed that Egrl expression in the ARC of $\mathrm{A}^{\mathrm{y}}$; Agrp $\mathrm{p}^{\mathrm{DTR} /{ }^{+}}$mice was significantly attenuated compared with that of $\operatorname{Agrp}^{\mathrm{DTR} /+}$ mice following DT treatment, suggesting that the melancortin signaling pathway in the ARC modulates Egrl-associated neuronal hyperexcitability (Fig. 1I and J and Fig. 2A).

Ablation of ARP neurons induces Egrl in other regions of the brain. Egrl expression was also analyzed in other brain regions that receive dense projections from ARP neurons. DT-treated $\operatorname{Agrp}^{\text {DTR }}$ mice showed significant Egrl induction in a number of these downstream areas, such as the PVN, medial preoptic area (MPO), hippocampal dentate gyrus (DG), lateral septum 


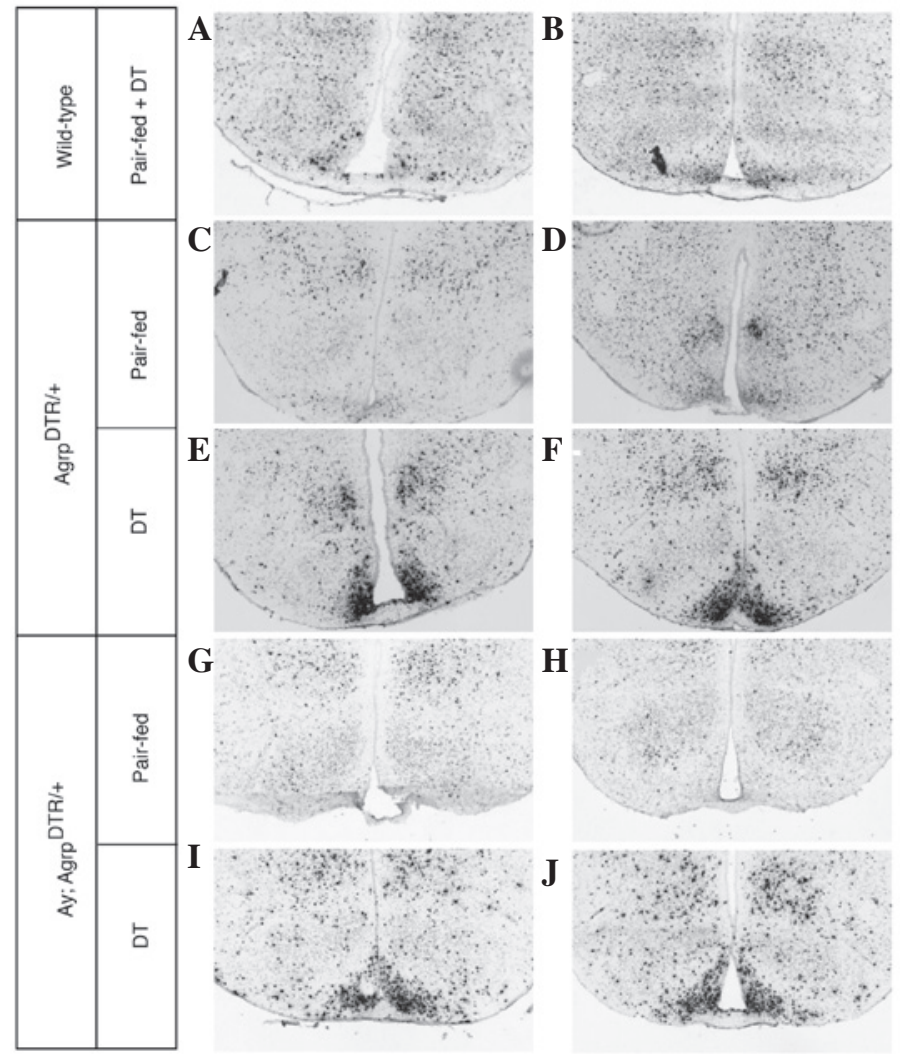

Figure 1. Profiling of early growth response factor-1 (Egrl) gene expression in the arcuate nucleus (ARC) following ablation of agouti-related peptide (ARP) neurons and chronic blockade of melanocortin signaling. Two representative brain sections show Egrl in situ hybridization in the ARC, one of the postsynaptic regions of ARP neurons, of (A and B) wild-type mice; (C and D) Agrp ${ }^{\mathrm{DTR} /+}$ mice pair-fed to the diptheria toxin (DT)-treated group or (E and F) treated with DT; $A^{\mathrm{y}} ; \operatorname{Agrp}^{\text {DTR } /+}$ mice pair-fed to the DT-treated group $(\mathrm{G}$ and H) or treated with DT (I and J). 3,3'-Diaminobenzidine staining; magnification, $\mathrm{x} 10$.
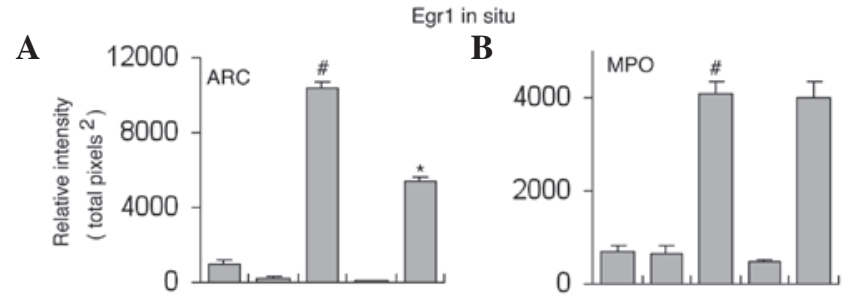

C

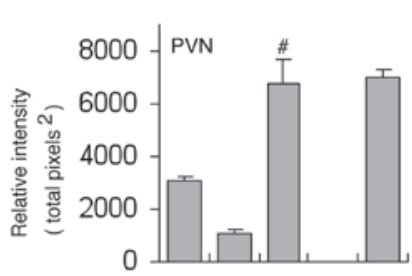

D

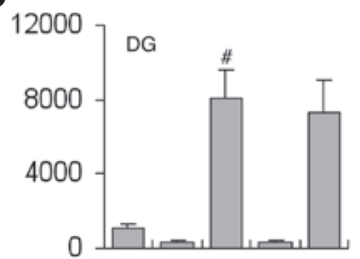

$\mathbf{E}$

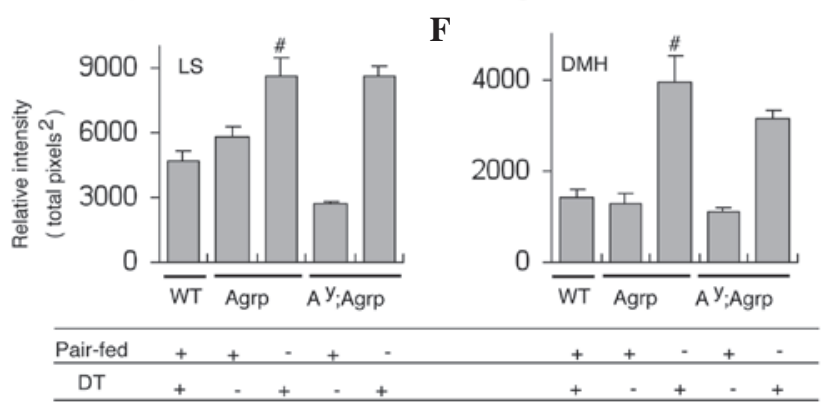

Figure 2. Quantified results for early growth response factor-1 (Egrl) in situ signals of agouti-related peptide neurons in (A) arcuate nucleus (ARC), (B) medial preoptic area (MPO), (C) paraventricular nucleus (PVN), (D) dentate gyrus (DG), (E) lateral sulcus (LS) and (F) dorsomedial hypothalamic nucleus (DMH) in selected postsynaptic regions from wild-type (WT) mice, $\mathrm{Agrp}^{\mathrm{DTR} /+}$ mice and $\mathrm{A}^{\mathrm{y}} ; \mathrm{Agrp}^{\mathrm{DTR} /+}$ mice with diptheria toxin (DT) treatment or pair-fed to the DT-treated mice. Histograms of Egrl expression are expressed as the mean of total pixels \pm SEM from at least 5 sections from 3-4 different mice per group. Statistical comparisons were made by analysis of variance. ${ }^{\#} \mathrm{P}<0.05$ vs. WT or pair-fed group; ${ }^{*} \mathrm{P}<0.05$ vs. the number in the ARC. 3,3'-Diaminobenzidine staining; magnification, $\mathrm{x} 10$. 


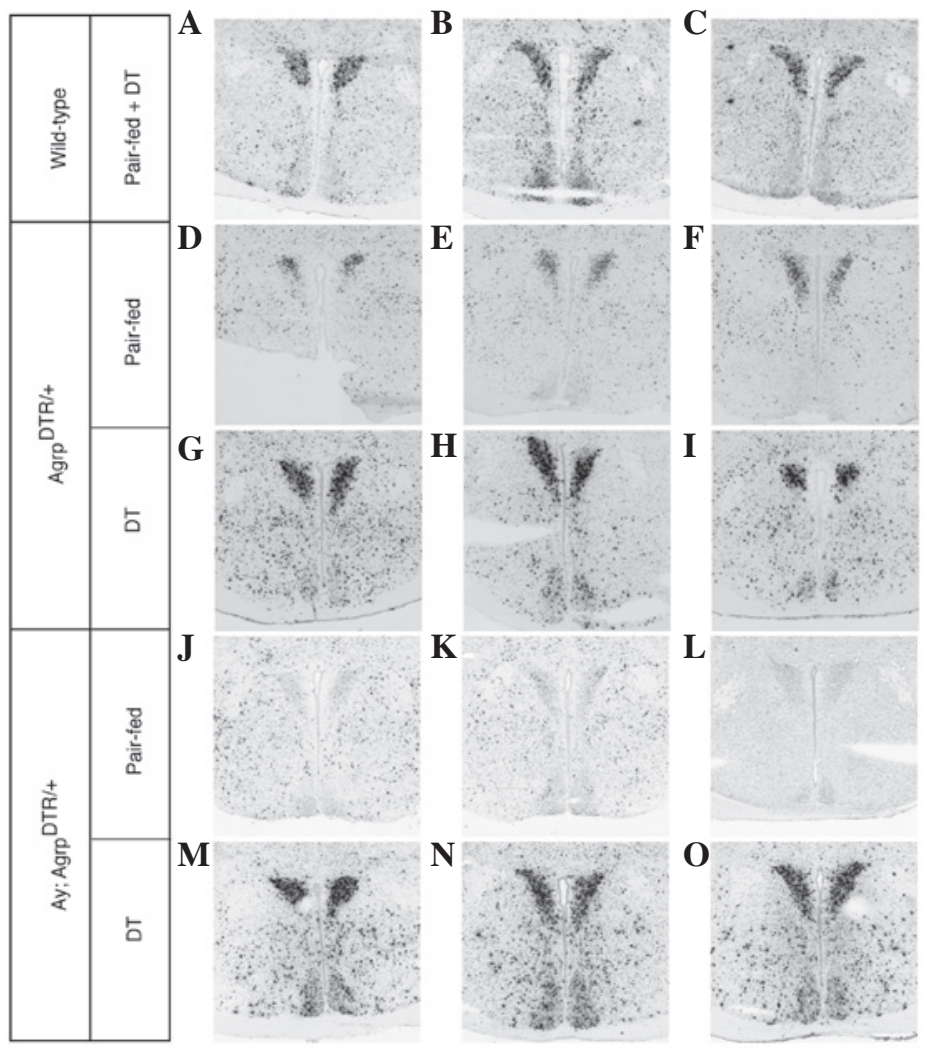

Figure 3. Profiling of early growth response factor-1 (Egrl) gene expression in the paraventricular nucleus (PVN) following ablation of agouti-related peptide (ARP) neurons and chronic blockade of melanocortin signaling. Three representative brain sections show Egrl in situ hybridization in the PVN, one of the postsynaptic regions of ARP neurons, of (A-C) wild-type mice; (D-F) Agrp ${ }^{\text {DTR } /+}$ mice pair-fed to the diptheria toxin (DT)-treated group or (G-I) treated with DT; and (J-L) A $\mathrm{A}^{\mathrm{y}}$; Agrp $\mathrm{DTR} /+^{+}$mice pair-fed to the DT-treated group or (M-O) treated with DT. 3,3'-Diaminobenzidine staining; magnification, x10.
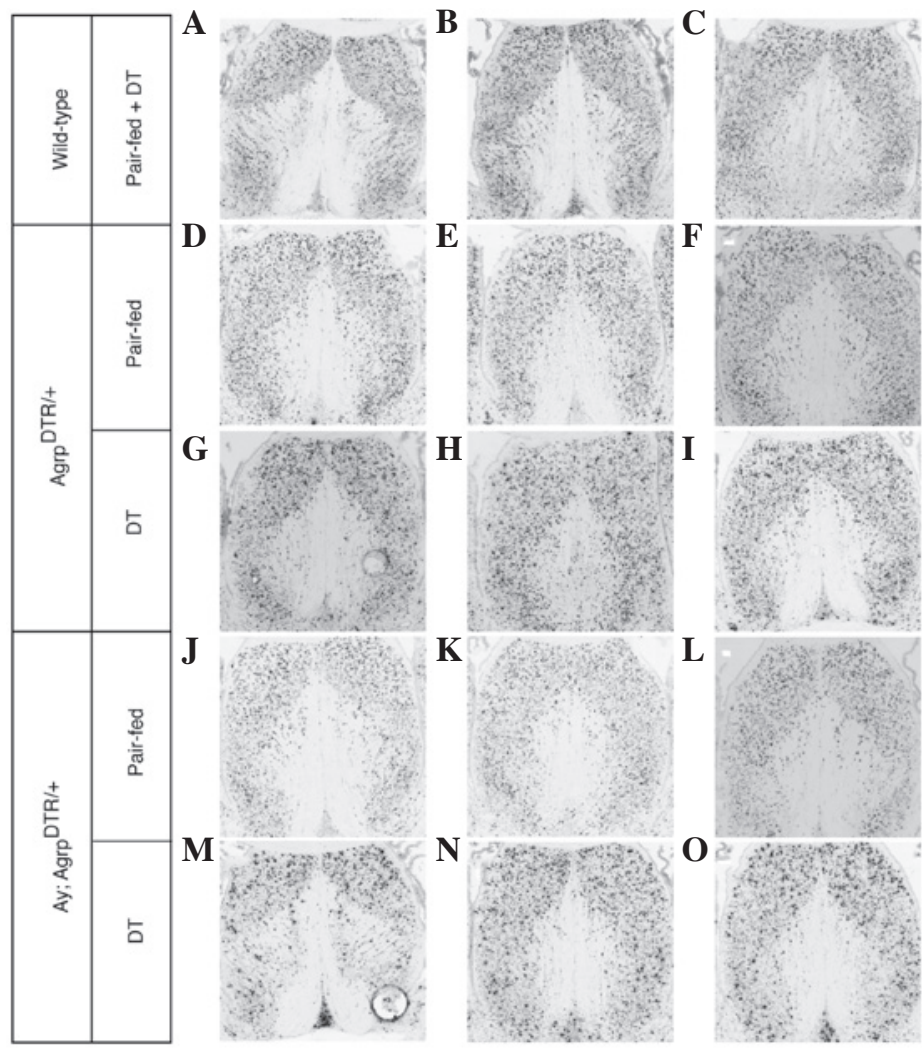

F
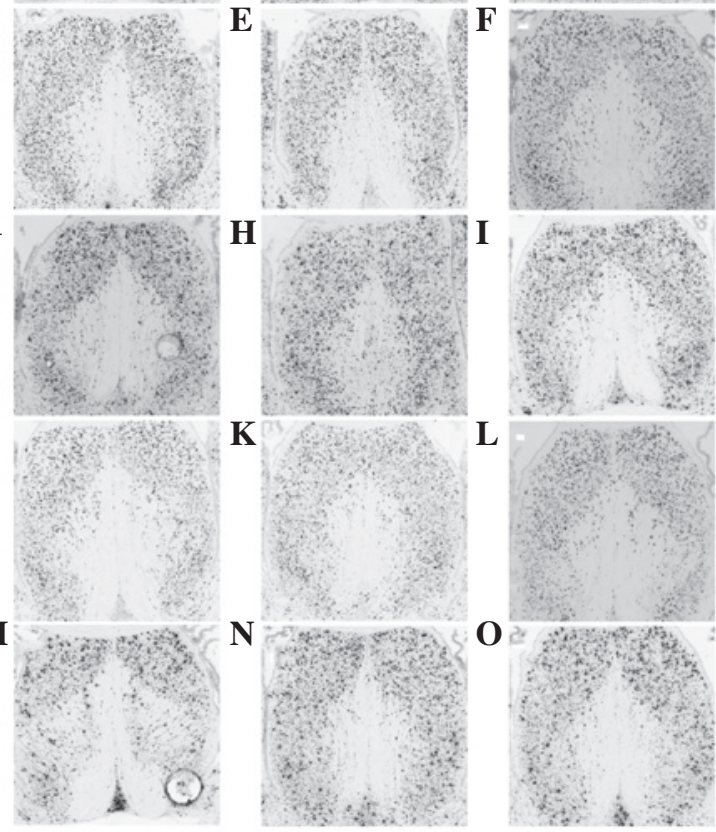

$\mathbf{L}$
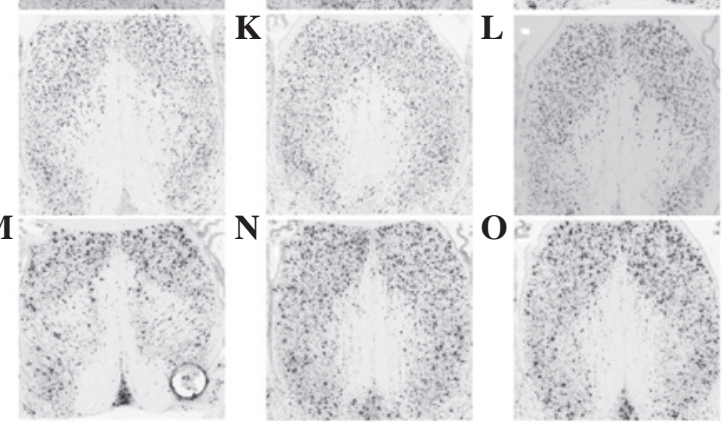

Figure 4. Profiling of early growth response factor-1 (Egrl) gene expression in the lateral sulcus (LS) following ablation of agouti-related peptide (ARP) neurons and chronic blockade of melanocortin signaling. Three representative brain sections show Egrl in situ hybridization in the LS, one of the postsynaptic regions of ARP neurons, of (A-C) wild-type mice; (D-F) Agrp ${ }^{\text {DTR } /+}$ mice pair-fed to the diptheria toxin (DT)-treated group or (G-I) treated with DT; and $(\mathrm{J}-\mathrm{L}) \mathrm{A}^{\mathrm{y}}$; Agrp ${ }^{\mathrm{DTR} /+}$ mice pair-fed to the DT-treated group or (M-O) treated with DT. 3,3'-Diaminobenzidine staining; magnification, x10. 


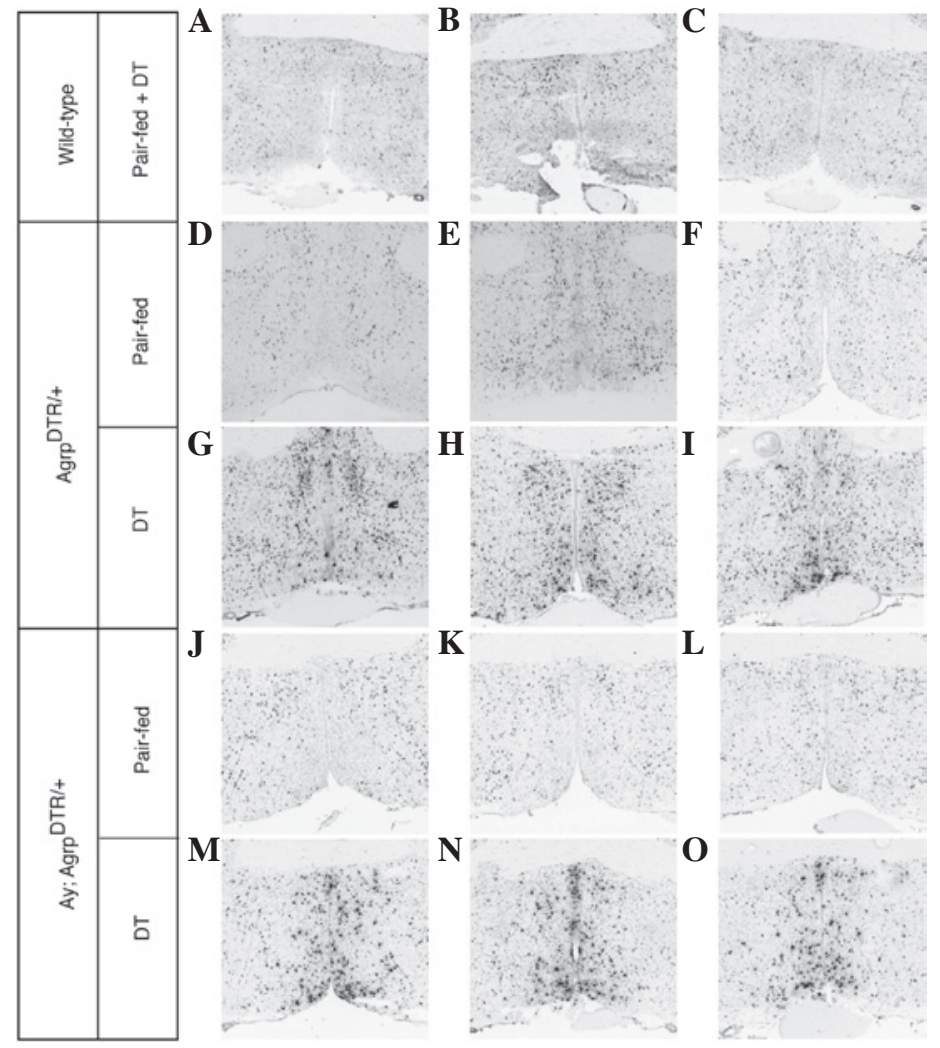

Figure 5. Profiling of early growth response factor-1 (Egrl) gene expression in the medial preoptic area (MPO) following ablation of agouti-related peptide (ARP) neurons and chronic blockade of melanocortin signaling. Three representative brain sections show Egrl in situ hybridization in the MPO, one of the postsynaptic regions of ARP neurons, of (A-C) wild-type mice; (D-F) Agrp ${ }^{\mathrm{DTR} /+}$ mice pair-fed to the diptheria toxin (DT)-treated group or (G-I) with DT

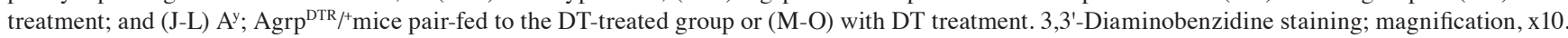
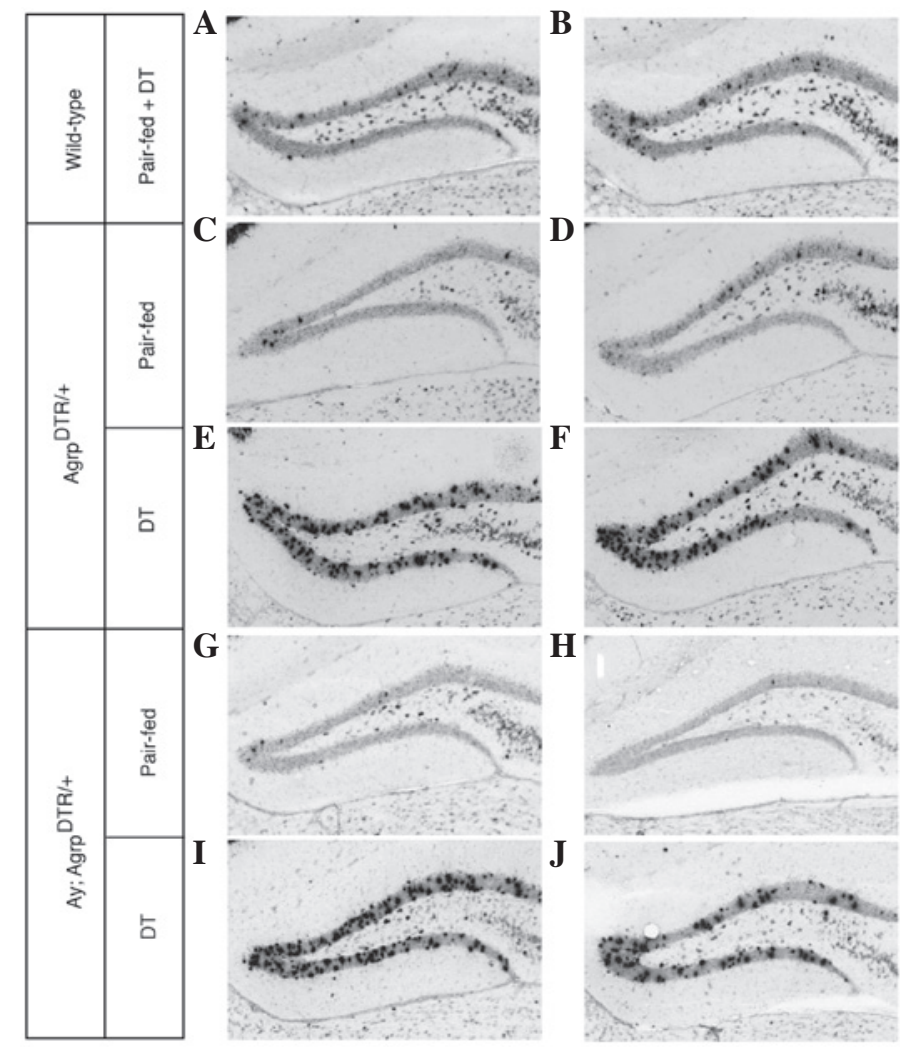

Figure 6. Profiling of early growth response factor-1 (Egrl) gene expression in the dentate gyrus (DG) follwing ablation of agouti-related peptide (ARP) neurons and chronic blockade of melanocortin signaling. Two representative brain sections show Egrl in situ hybridization in the DG, one of the postsynaptic regions of ARP neurons, of (A and B) wild-type mice; (C and D) Agrp ${ }^{\mathrm{DTR} /+}$ mice with pair-fed to the diptheria toxin (DT)-treated group or (E and F) treated with DT; and $(\mathrm{G}$ and $\mathrm{H}) \mathrm{A}^{\mathrm{y}}$; Agrp ${ }^{\mathrm{DTR} /{ }^{+}}$mice pair-fed to the DT-treated group (I and J) or treated with DT. 3,3'-Diaminobenzidine staining; magnification, $\mathrm{x} 10$. 


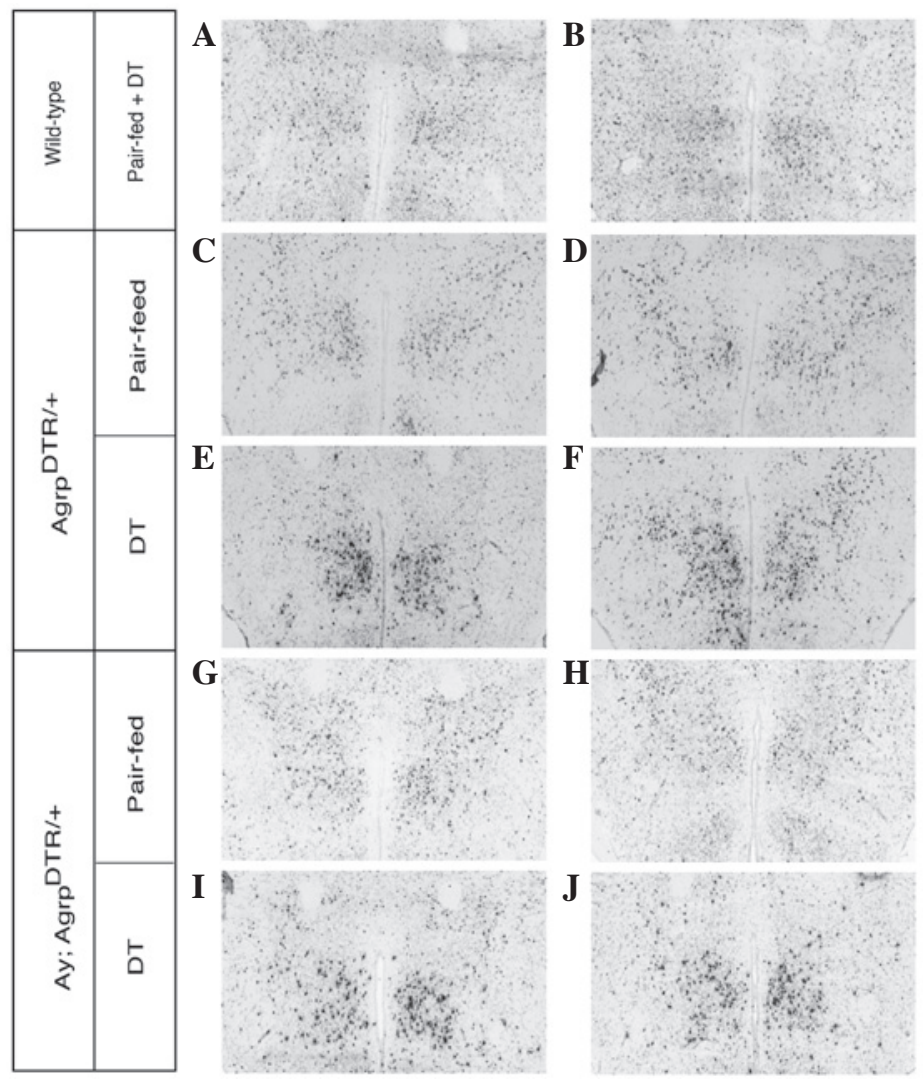

Figure 7. Profiling of early growth response factor-1 (Egrl) gene expression in the dorsomedial hypothalamic nucleus (DMH) following ablation of agouti-related peptide (ARP) neurons and chronic blockade of melanocortin signaling. Two representative brain sections show Egrl in situ hybridization in the DMH, one of the postsynaptic regions of ARP neurons, of (A and B) wild-type mice; (C and D) $\mathrm{Agrp}^{\mathrm{DTR} /{ }^{+}}$mice pair-fed to the diptheria toxin (DT)-treated group or (E and F) treated

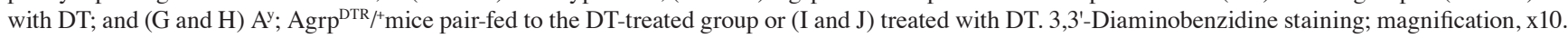

(LS), and DMH, compared with either WT control or pair-fed Agrp $^{\text {DTR }}$ mice (Fig. 2B-F and Figs. 3-7). However, no significant difference was identified in Egrl induction between $\operatorname{Agrp}^{\mathrm{DTR} /+}$ mice and $\mathrm{A}^{\mathrm{y}}$; Agrp ${ }^{\mathrm{DTR} /+}$ mice in the PVN, MPO, DG, LS and DMH nuclei when ARP neurons were ablated (Fig. 2B-F and Figs. 3-7). This suggests that melanocortin signaling does not contribute to Egrl induction and excitability of postsynaptic neurons in these regions.

\section{Disscussion}

ARP is an orexigenic peptide that stimulates robust feeding, following intracerebroventricular administration (1) or direct injection into the PVN or DMH (4). Ablation of ARP neurons in adult mice inhibits feeding behavior and results in starvation within a short period of time $(9,10)$, indicating that ARP neurons are essential for normal body weight regulation. Within the central nervous system (CNS), ARP is expressed exclusively in a small population of neurons located in the ARC that also co-release NPY and GABA (2). However, the molecular and cellular mechanisms underlying the orexigenic effect of ARP neurons are still poorly understood and currently under investigation (22). In the present study, it was demonstrated that the ablation of ARP neurons markedly induced Egrl expression in the majority of known targets of POMC and ARP neurons, indicating that the loss of ARP neurons leads to disinhibition of postsynaptic neurons, which eventually results in anorexia. Egr1 has been observed to stimulate CART expression in certain types of neurons $(17,23)$. CART peptides are widely distributed in the CNS and are known to suppress food intake $(24,25)$ and stimulate Fos expression in a number of brain areas when administered centrally (26,27). Leptin-induced Egrl expression has been shown to increase the sensitivity of vagal afferent neurons to CCK, thereby inhibiting food intake $(17,27)$. Therefore, it was suggested that Egrl-induced CART expression and hypersensitivity to CCK was responsible, at least partially, for the anorexia phenotype in ARP neuron-ablated mice, although functional analysis of the ARP neural circuitry is required to test this hypothesis.

POMC neurons in the ARC produce $\alpha-\mathrm{MSH}$, an anorexigenic peptide that activates MC4Rs on postsynaptic cells (18). Activation of this melanocortin pathway inhibits feeding and stimulates metabolism. Studies have suggested that ARP neurons counteract the POMC signaling pathway by directly inhibiting POMC neurons via GABA release (28) and antagonizing the binding of melanocortin to MC4R (18). In the results of the present study, Egrl induction in the ARC was attenuated in mice with an $\mathrm{A}^{\mathrm{y}}$ genetic background when ARP neurons were ablated. This indicated that profound Egrl expression in the ARC induced by ablation of ARP neurons is mediated through the melanocortin pathway. By contrast, other downstream regions that ARP neurons project to demonstrated no change in Egrl induction under $\mathrm{A}^{\mathrm{y}}$ background, suggesting that other unknown signaling pathways are responsible for Egrl induction in these regions. 
In conclusion, the results suggested that the deletion of ARP neurons leads to robust induction of Egrl expression in the majority of common target regions of ARP and POMC neurons. The induction of Egrl is dependent on the melanocortin signaling pathway in the ARC, but not in other downstream regions in the brain. It was suggested that Egrl induction may be involved in the central control of appetite mediated by ARP neurons. Further analysis of the Egr1 signaling cascade is required to elucidate the function of postsynaptic targets of ARP and POMC neurons in the control of energy metabolism, which may be therapeutically beneficial.

\section{Acknowledgements}

This study was supported by the Hunan Science \& Technology Project (grant no. 2011FJ3094).

\section{References}

1. Rossi M, Kim MS, Morgan DG, Small CJ, Edwards CM, Sunter D, Abusnana S, Goldstone AP, Russell SH, Stanley SA, et al: A C-terminal fragment of Agouti-related protein increases feeding and antagonizes the effect of alpha-melanocyte stimulating hormone in vivo. Endocrinology 139: 4428-4431, 1998.

2. Broberger C, Johansen J, Johansson C, Schalling M and Hökfelt T: The neuropeptide Y/agouti gene-related protein (AGRP) brain circuitry in normal, anorectic, and monosodium glutamate-treated mice. Proc Natl Acad Sci USA 95: 15043-15048, 1998

3. Haskell-Luevano C, Chen P, Li C, Chang K, Smith MS, Cameron JL and Cone RD: Characterization of the neuroanatomical distribution of agouti-related protein immunoreactivity in the rhesus monkey and the rat. Endocrinology 140: 1408-1415, 1999.

4. Kim MS, Rossi M, Abusnana S, Sunter D, Morgan DG, Small CJ, Edwards CM, Heath MM, Stanley SA, Seal LJ, et al Hypothalamic localization of the feeding effect of agouti-related peptide and alpha-melanocyte-stimulating hormone. Diabetes 49: 177-182, 2000.

5. Morton GJ, Cummings DE, Baskin DG, Barsh GS and Schwartz MW: Central nervous system control of food intake and body weight. Nature 443: 289-295, 2006.

6. Barsh GS and Schwartz MW: Genetic approaches to studying energy balance: perception and integration. Nat Rev Genet 3: 589-600, 2002

7. Kalra SP, Dube MG, Pu S, Xu B, Horvath TL and Kalra PS: Interacting appetite-regulating pathways in the hypothalamic regulation of body weight. Endocr Rev 20: 68-100, 1999.

8. Ollmann MM, Wilson BD, Yang YK, Kerns JA, Chen Y, Gantz I and Barsh GS: Antagonism of central melanocortin receptors in vitro and in vivo by agouti-related protein. Science 278 : $135-138,1997$.

9. Luquet S, Perez FA, Hnasko TS and Palmiter RD: NPY/AgRP neurons are essential for feeding in adult mice but can be ablated in neonates. Science 310: 683-685, 2005.

10. Gropp E, Shanabrough M, Borok E, Xu AW, Janoschek R, Buch T, Plum L, Balthasar N, Hampel B, Waisman A, et al: Agouti-related peptide-expressing neurons are mandatory for feeding. Nat Neurosci 8: 1289-1291, 2005.

11. Bewick GA, Gardiner JV, Dhillo WS, Kent AS, White NE, Webster Z, Ghatei MA and Bloom SR: Post-embryonic ablation of AgRP neurons in mice leads to a lean, hypophagic phenotype. FASEB J 19: 1680-1682, 2005.
12. Xu AW, Kaelin CB, Morton GJ, Ogimoto K, Stanhope K, Graham J, Baskin DG, Havel P, Schwartz MW and Barsh GS: Effects of hypothalamic neurodegeneration on energy balance. PLoS Biol 3: e415, 2005.

13. Wu Q, Boyle MP and Palmiter RD: Loss of GABAergic signaling by AgRP neurons to the parabrachial nucleus leads to starvation. Cell 137: 1225-1234, 2009.

14. Sukhatme VP, Cao XM, Chang LC, Tsai-Morris $\mathrm{CH}$, Stamenkovich D, Ferreira PC, Cohen DR, Edwards SA, Shows TB, Curran T et al: A zinc finger-encoding gene coregulated with c-fos during growth and differentiation, and after cellular depolarization. Cell 53: 37-43, 1988.

15. Cole AJ, Saffen DW, Baraban JM and Worley PF: Rapid increase of an immediate early gene messenger RNA in hippocampal neurons by synaptic NMDA receptor activation. Nature 340: 474-476, 1989

16. Beckmann AM and Wilce PA: Egr transcription factors in the nervous system, Neurochem Int 31: 477-510; discussion 517-476, 1997.

17. de Lartigue G, Lur G, Dimaline R, Varro A, Raybould H and Dockray GJ: EGR1 Is a target for cooperative interactions between cholecystokinin and leptin, and inhibition by ghrelin, in vagal afferent neurons. Endocrinology 151: 3589-3599, 2010.

18. Cone RD: Anatomy and regulation of the central melanocortin system. Nat Neurosci 8: 571-578, 2005.

19. Michaud EJ, Bultman SJ, Stubbs LJ and Woychik RP: The embryonic lethality of homozygous lethal yellow mice (Ay/Ay) is associated with the disruption of a novel RNA-binding protein. Genes Dev 7: 1203-1213, 1993.

20. Aher CV, Duwaerts CC, Akama KT and Lucas LR: Effects of acute diuresis stress on egr-1 (zif268) mRNA levels in brain regions associated with motivated behavior. Brain Res Bull 81: 114-119, 2010.

21. Paxinos G and Franklin KBJ (eds): The Mouse Brain in Stereotaxic Coordinates. 2nd edition. Academic Press, Waltham, MA, 2001.

22. Liu T, Wang Q, Berglund ED and Tong Q: Action of neurotransmitter: A key to unlock the AgRP neuron feeding circuit. Front Neurosci 6: 200, 2013

23. Dockray GJ and Burdyga G: Plasticity in vagal afferent neurones during feeding and fasting: mechanisms and significance. Acta Physiol (Oxf) 201: 313-321, 2011.

24. Rogge G, Jones D, Hubert GW, Lin Y and Kuhar MJ: CART peptides: regulators of body weight, reward and other functions. Nat Rev Neurosci 9: 747-758, 2008.

25. Koylu EO, Couceyro PR, Lambert PD, Ling NC, DeSouza EB and Kuhar MJ: Immunohistochemical localization of novel CART peptides in rat hypothalamus, pituitary and adrenal gland. J Neuroendocrinol 9: 823-833, 1997.

26. Stanley SA, Small CJ, Murphy KG, Rayes E, Abbott CR, Seal LJ, Morgan DG, Sunter D, Dakin CL, Kim MS, Hunter R, Kuhar M, Ghatei MA and Bloom SR: Actions of cocaine- and amphetamine-regulated transcript (CART) peptide on regulation of appetite and hypothalamo-pituitary axes in vitro and in vivo in male rats. Brain Res 893: 186-194, 2001.

27. de Lartigue G, Barbier de la Serre C, Espero E, Lee J and Raybould HE: Leptin resistance in vagal afferent neurons inhibits cholecystokinin signaling and satiation in diet induced obese rats. PLoS One 7: e32967, 2012.

28. Cowley MA, Smart JL, Rubinstein M, Cerdán MG, Diano S, Horvath TL, Cone RD and Low MJ: Leptin activates anorexigenic POMC neurons through a neural network in the arcuate nucleus. Nature 411: 480-484, 2001. 